\title{
Encefalitis equina del oeste
}

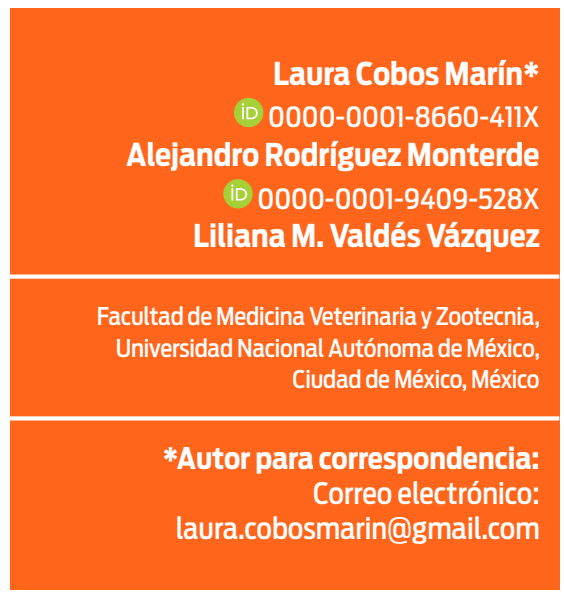

Aceptado: 2019-09-27

Publicado: $2019-09-30$

Información y declaraciones adicionales en la página 9

(a) Derechos de autor: Laura Cobos Marín et al. 2019

acceso abierto $\mathbf{2}$



Distribuido bajo una Licencia Creative Commons Atribución 4.0 Internacional (CC-BY 4.0)

\section{Resumen}

La encefalitis equina del oeste (EEO) --al igual que las encefalomielitis del este (EEE) y venezolana (EEV)-- es una infección viral zoonótica que se transmite por mosquitos vectores. Su notificación debe ser inmediata y obligatoria. A pesar del nombre que se le ha dado, el caballo es sólo un huésped incidental. La manifestación clínica de las tres encefalitis es muy similar, por lo que se requiere de una correcta toma y envío de muestras al laboratorio para lograr un diagnóstico diferencial. Los ciclos de infección se presentan de dos formas: enzoótica, en la que el virus permanece por largos períodos circulando entre los huéspedes reservorios y el vector transmisor; y epizoótica, que involucra a los huéspedes incidentales y a los vectores transmisores. Los principales signos en caballos son alteración del comportamiento, dificultad visual, deambulación, caminata en círculos, dificultad en la deglución, ataxia, paresia, parálisis y convulsiones. No existe tratamiento, por lo que su manejo se enfoca a la terapia de soporte, con un pronóstico desfavorable, ya que la tasa de mortalidad (dependiendo de la encefalitis de la que se trate) puede llegar al 90\%. La EEV es endémica en México y es la que presenta más riesgo, ya que, a diferencia de las otras dos, los caballos afectados suelen desarrollar viremia, por lo que pueden transmitir la enfermedad a través del piquete de mosco a otros huéspedes animales o al ser humano. En cuanto a las EEE y EEO aún no se han reconocido oficialmente en el territorio mexicano. Sin embargo, en marzo del presente año, se detectaron 44 casos de EEO en equinos en Nayarit. Dado que la única vacuna disponible y autorizada en México es la utilizada para prevenir la EEV, las medidas para disminuir el riesgo de infección por la EEE y la EEO se centran en alojar a los caballos en caballerizas controladas, especialmente durante los horarios de elevada actividad de los mosquitos.

Palabras clave: Virus, Encefalitis equina del oeste, Encefalomielitis equinas, EEO, EEV, EEE, Control, Ciclos de infección

\section{Cómo citar este artículo:}

Cobos Marín L, Rodríguez Monterde A, Valdés Vázquez LM. Encefalitis equina del oeste. Vet México OA. 2019;6(3). doi: 10.22201/fmvz.24486760e.2019.3.785 


\section{Encefalomielitis equinas}

Las encefalomielitis equinas del este (EEE), del oeste (EEO) y venezolana (EEV) se han identificado a lo largo del continente americano. Son infecciones zoonóticas, transmitidas por mosquitos vectores, cuyos agentes etiológicos son virus ARN, que pertenecen a la familia Togaviridae, del género Alphavirus. Los huéspedes reservorios son principalmente aves y roedores, mientras que los equinos y los humanos son huéspedes incidentales.

En los caballos, las tres encefalomielitis tienen una presentación clínica muy similar. Algunos individuos desarrollan infecciones asintomáticas o casos leves sin signos neurológicos, y son los sujetos más jóvenes o inmunocomprometidos los que comúnmente muestran signos clínicos más graves. Los signos incluyen fiebre de moderada a alta, anorexia, depresión, falta de apetito, déficit en la actividad de los nervios craneales (parálisis facial, debilidad de la lengua y dificultad para tragar), cambios de comportamiento (agresión, mutilación o somnolencia), anormalidades en la marcha o signos severos en el sistema nervioso central, tales como recargar o presionar la cabeza contra objetos, desorientación, ataxia, ceguera, movimientos circulares y convulsiones. ${ }^{1}$ También se observan episodios de excitación, prurito intenso, movimientos de carrera cuando están postrados y paresia. ${ }^{2}$

Los periodos de incubación y la tasa de mortalidad en equinos y humanos (documentadas en EUA) son variables entre las tres enfermedades y se presentan en la Tabla 1.

\section{Ciclo de infección viral y etiología}

Los Arbovirus causantes de las encefalitis equinas toman su nombre del inglés: arthropod-borne viruses, ya que son transmitidos principalmente por mosquitos hematófagos. Los ciclos de infección se presentan de dos formas: enzóotica, en la que el virus permanece por largos períodos circulando entre los huéspedes reservorios (aves, roedores y ocasionalmente reptiles) y el vector transmisor (mosco); y epizoótica, que involucra a los huéspedes incidentales (principalmente al caballo y al humano) y a los vectores transmisores (que pueden ser los mismos moscos que participan en el ciclo enzoótico, o de otra especie). El ciclo de infección epizoótico puede aparecer y desaparecer de forma abrupta, o por períodos prolongados. Esto depende de la época del año, de la presencia de los vectores transmisores y de las

Tabla 1. Periodos de incubación y tasa de mortalidad en equinos y humanos en encefalitis equinas venezolana, del este y del oeste (EEV, EEE y EEO) diagnosticadas en los Estados Unidos.

\begin{tabular}{|c|c|c|c|c|c|c|}
\hline \multirow{2}{*}{ Especie } & \multicolumn{3}{|c|}{ Período de incubación } & \multicolumn{3}{|c|}{ Letalidad } \\
\hline & EEV & EEE & EEO & EEV & EEE & EEO \\
\hline Caballo & 1 a 3 días & 18 a 24 horas & 1 a 3 semanas & $\begin{array}{l}20-40 \% \\
80-83 * \%\end{array}$ & $\begin{array}{l}65-75 \% \\
90 \% *\end{array}$ & $20-50 \%$ \\
\hline Humano & 2 a 5 días & 7 a 10 días & 5 a 10 días & $\begin{array}{c}50-70 \% \\
\text { en menores } \\
\text { de } 15 \text { años y } \\
\text { mayores de } 55 \text {. }\end{array}$ & 3-5 \% en niños & $\begin{array}{c}9 \% \\
30 \% \text { en } \\
\text { mayores de } 65 \\
\text { años }\end{array}$ \\
\hline
\end{tabular}

* En casos de meningoencefalomielitis severa. Adaptado de Mesa et al. ${ }^{41}$ 
variantes virales que estén circulando. ${ }^{3}$ En la figura 1 se muestran los ciclos enzoótico y epizoótico de las encefalitis equinas.

En particular en la EEV, el ciclo enzoótico entre los reservorios (roedores y otros vertebrados) y los vectores (Culex melanoconion) se mantiene en climas húmedos y tropicales; mientras que el ciclo epizoótico se presenta cuando surgen variantes virales capaces de infectar a huéspedes incidentales como el caballo, y cuando se detecta presencia de vectores como Aedes y Psophora spp. Además, debido a que los caballos suelen tener altos niveles de virus en sangre (viremia), pueden transmitir la enfermedad a través del piquete de mosco hacia otros huéspedes como el ser humano, perros, gatos, cerdos o aves. ${ }^{3}$

En la EEE, el ciclo enzoótico se mantiene en ambientes húmedos entre el vector Culistea melanura y roedores, reptiles y aves paseriformes (como principal reservorio). Estas aves alcanzan altos niveles de viremia, por lo que son capaces de mantener el ciclo enzoótico, o bien de provocar el ciclo epizoótico en sus huéspedes incidentales: caballos, faisanes y humanos, a través del piquete de los mosquitos vectores Aedes o Coquilettidia. Al no desarrollar altos niveles de viremia, los huéspedes incidentales no pueden a su vez transmitir la enfermedad. ${ }^{3}$

En lo que concierne a la EEO, el ciclo enzoótico se mantiene entre el vector Culex tarsalis y las aves paseriformes, que pueden provocar los ciclos epizoóticos cuando hay presencia de mosquitos Aedes. Además, se ha sugerido que los roedores y lagomorfos también pueden participar como reservorios amplificadores cuando son infectados por estos mosquitos. El ciclo epizoótico ocurre en los caballos y humanos como huéspedes finales (que no transmiten la enfermedad). ${ }^{3}$

\section{Características y replicación viral}

Los agentes causales de las encefalomielitis equinas son virus envueltos, esféricos e icosaédricos, de 65 a 70 nm de diámetro, con genoma tipo ARN no segmentado, y de polaridad positiva, con un tamaño aproximado de $11.5 \mathrm{~kb}$. Los dos tercios del genoma en su porción terminal $5^{\prime}$ codifican para cuatro proteínas no estructurales (nsP1 a nsP4) que conforman un complejo de enzimas requeridas para la replicación viral. El resto del genoma codifica para proteínas estructurales: la proteína $C$ de la cápside, y las glucoproteínas de la envoltura E1 y E2, que son inmunogénicas; de éstas, la E2 presenta la mayor variabilidad antigénica. ${ }^{4}$ Como todos los virus envueltos, son susceptibles a desinfectantes comunes tales como el hipoclorito de sodio al 1\%, el etanol al 70\%, el glutaraldehído y el formaldehído al $2 \%$, y no sobreviven fuera del huésped. ${ }^{4}$

\section{Encefalitis equina del oeste Historia}

En marzo del presente año, el Servicio Nacional de Sanidad, Inocuidad y Calidad Agroalimentaria (Senasica), a través del Laboratorio de Alta Seguridad (BSL3), ubicado en la Ciudad de México, ${ }^{5}$ confirmó que se presentaron 41 casos de caballos afectados por el virus de encefalitis equina del oeste (VEEO) en los poblados de Mexpan, municipio de Ixtlán del Río, y Ahuacatlán, en Nayarit. Inmediatamente se activó un operativo y la vigilancia en equinos, aves (silvestres y domésticas) 


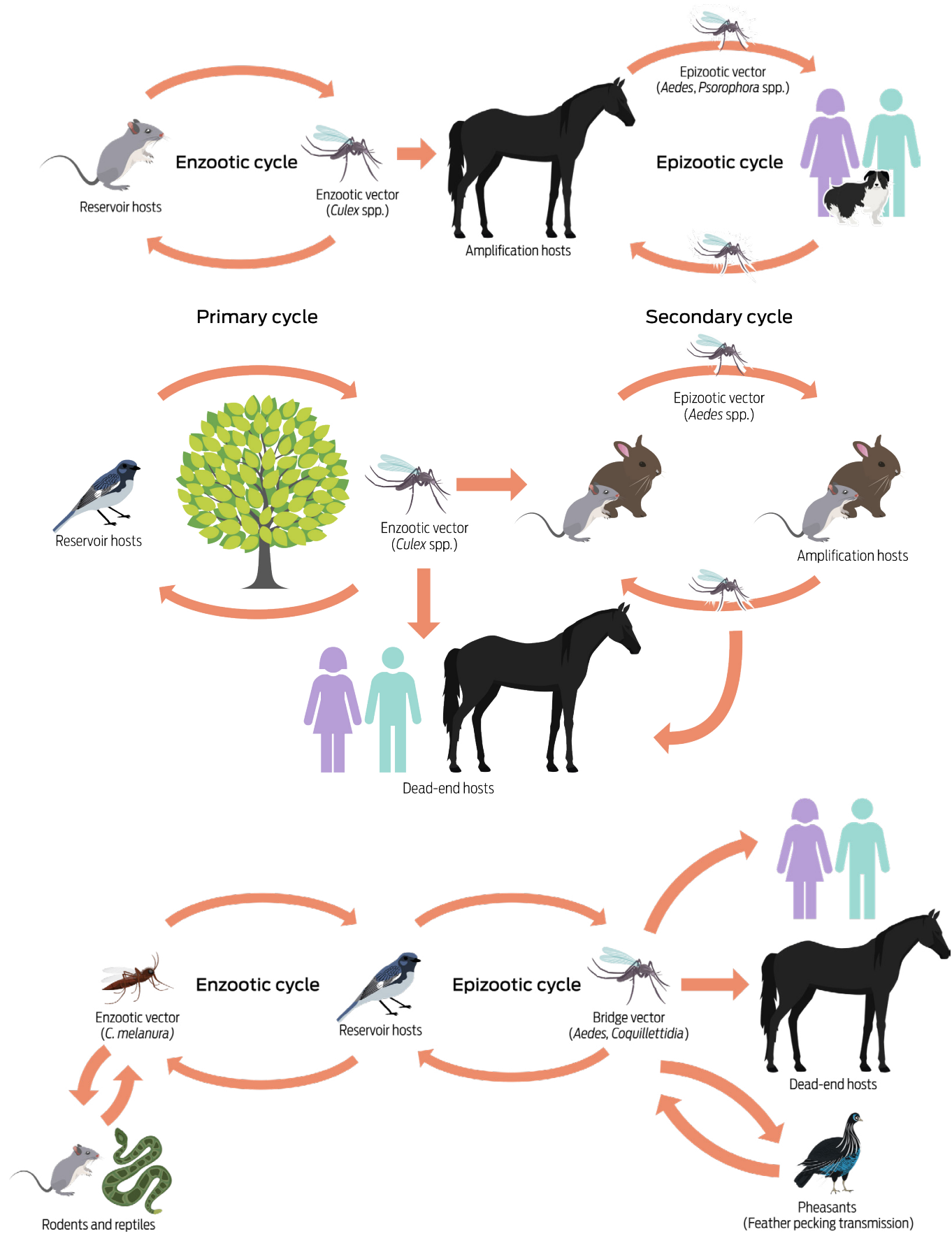

Figura 1. Ciclos enzoótico y epizoótico de las encefalitis equinas. a) EEV. El ciclo de transmisión enzoótica se mantiene entre roedores y otros vertebrados (como ratas, murciélagos y zarigüeyas), que actúan como reservorios, y los mosquitos del género Culex, que son los vectores principales. En el ciclo epizoótico de esta enfermedad, los vectores son los moscos de los géneros Aedes y Psophora, y los huéspedes amplificadores son los caballos (que pueden presentar altos niveles de viremia); b) EEO. El ciclo enzoótico se mantiene entre las aves paseriformes como reservorios, y el mosquito $C$. tarsalis como vector. En el ciclo epizoótico, las aves paseriformes participan como huéspedes amplificadores, mientras que los caballos y los humanos son huéspedes finales. Los roedores y lagomorfos, pueden también fungir como huéspedes de amplificación cuando se infectan por mosquitos Aedes; c) EEE. En hábitats pantanosos el ciclo enzoótico se mantiene entre aves paseriformes (que participan como reservorios) y los huéspedes amplificadores. Los vectores principales en este tipo de ciclo son los mosquitos Culiseta melanura. En algunos países de sudamérica los roedores y los reptiles pueden actuar también como reservorios. Debido a que las aves paseriformes desarrollan altos niveles de viremia, son capaces de infectar a un gran número de vectores. Los humanos y los caballos son hospederos finales, pues no desarrollan un nivel de viremia suficiente para transmitir el virus. Adaptado de Go et al. ${ }^{3}$ 
y mosquitos, en un contorno de $10 \mathrm{~km}$ a la redonda del sitio donde se presentaron los casos. Se considera, por lo tanto, importante realizar una revisión particular de la historia de esta enfermedad, así como de sus signos clínicos, diagnóstico y control, para estar debidamente informados por si esta situación se presenta nuevamente en México.

La encefalitis equina del oeste (EEO) se ha diagnosticado en EUA, Canadá y Sudamérica (incluyendo Guayana, Ecuador, Brasil, Uruguay y Argentina), y existe incluso un subtipo viral con un reservorio endémico distribuido por Sudamérica (Weaver et al., 1997)S. Lustig, E. G. Strauss, and J. H. Strauss, Proc. Natl. Acad. Sci. USA 85:5997-6001, 1988. ${ }^{6}$ En México, el virus que causa la EEO se encuentra latente desde hace más de 60 años. ${ }^{5}$ En general, el grado de diseminación viral depende de la dinámica de transmisión y de la distribución del vector (mosquito) y del hospedador, por lo que la enfermedad está modulada por factores ambientales. ${ }^{3}$ La presencia de agua, lluvias y el calor tienden a aumentar las poblaciones de vectores. Además, un clima cálido acorta el periodo de incubación y aumenta la tasa de replicación del virus en el vector. ${ }^{7}$

El brote de EEO más significativo ocurrió en 1941 en EUA, ya que se diagnosticaron más de 3,000 casos en humanos. ${ }^{8}$ Entre 1955 y 1971 se diagnosticaron 762 personas afectadas por esta enfermedad, con entre 20 y 650 casos confirmados cada año por pruebas de laboratorio. ${ }^{9}$ En la actualidad, siguen observándose casos esporádicos de encefalitis en caballos, dispersos en una amplia área geográfica. ${ }^{8}$

La presencia de los casos en equinos y humanos es más común entre abril y septiembre, con picos en julio y agosto. ${ }^{8}$ En humanos se ha observado que la enfermedad es más habitual en hombres que en mujeres. Las tasas de infectividad son de 1:1,000 para adultos; 1:58 para niños de entre 1 y 4 años, y 1:1 en niños de menor edad. ${ }^{10}$

En lo que concierne a México, en 1965 se realizó un estudio serológico se encontró una seroprevalencia para EEO del 1.1\% en Sonora, y del $2.7 \%$ en Veracruz. ${ }^{11,12}$ Sin embargo, los estudios de seroprevalencia no reflejan el estatus real del hospedador, ya que el virus puede o no estar presente en el animal. Recientemente, en el mes de marzo de 2019, el Servicio Nacional de Sanidad, Inocuidad y Calidad Agroalimentaria (Senasica) informó a la Organización Mundial de Salud Animal (OIE) el hallazgo de este virus en 44 caballos de 5 municipios del estado de Nayarit. ${ }^{5}$

\section{Método de transmisión}

Tal como se mencionó anteriormente, el virus de la EEO cumple su ciclo en las poblaciones de aves y se transmite por mosquitos, alternando particularmente entre gorriones y mosquitos culícidos (principalmente el Culex tarsalis). Otros vectores importantes son: Culiseta melanura, Aedes melanimon, Aedes dorsalis y Aedes campestris. El virus de la EEO también puede alternar entre el mosquito $A$. melanimon y la liebre de cola negra (Lepus califomicus), después de la infección ave/mosquito. Los caballos infectados con este virus no desarrollan una viremia significativa $y$, por lo tanto, no transmiten la enfermedad a otros equinos ni a otras especies animales o a humanos. Sin embargo, la infección en los caballos suele ser indicativa de que el virus se encuentra activo en esa zona geográfica. 


\section{Infecciones en otras especies}

Aves. Las aves, en particular las correspondientes al orden de las paseriformes, son consideradas como el hospedador central en la ecología del virus de la EEO, ya que actúan como un sistema amplificador de la carga viral, que permite la infección de nuevos vectores. ${ }^{13}$ Estudios realizados en distintas aves muestran que 11 de las 20 especies que fueron inoculadas de forma experimental sobrevivieron la infección por más de dos semanas y se desempeñaron exitosamente como hospedadores y amplificadores del virus. ${ }^{14}$ En general, las aves cursan una infección asintomática, aunque se han observado signos clínicos como anorexia, letargo, pérdida de peso, diarrea, enteritis hemorrágica, signos neurológicos y muerte súbita. En pavos de postura se observa una disminución en la producción de huevo o en su calidad. ${ }^{15}$ En infecciones crónicas puede manifestarse una pérdida de la capacidad motriz, que les impide volar para conseguir alimento o mueren en los procesos migratorios. ${ }^{16,17}$

Ratones. La severidad y letalidad tras la infección por EEO en ratones depende de la variante viral y de la vía de inoculación, así como de la edad y cepa de los ratones. El virus puede transmitirse de forma experimental por aerosoles, vía subcutánea y vía intraperitoneal, y los periodos de incubación van de 2 a 7 días. ${ }^{18-21}$ Las lesiones histopatológicas características observadas en la mayoría de los casos consisten en necrosis neuronal laminar o multifocal, edema, infiltración de linfocitos en las meninges y en áreas subependimales. La gravedad de estas lesiones depende de la virulencia de la cepa viral, que afecta el tiempo de sobrevida. ${ }^{19}$ En ratones de 3 a 4 semanas de edad pueden encontrarse además lesiones en los pulmones, el hígado y el corazón. ${ }^{20}$

Humanos. Los seres humanos son hospedadores incidentales y finales en el ciclo de transmisión de la EEO, dado que los niveles de viremia son insuficientes para infectar a otros mosquitos. Existen también informes de transmisión transplacentaria, con la consecuente infección por vía congénita en los neonatos. ${ }^{22}$ El periodo de incubación es de 2 a 7 días y la tasa de letalidad es del 3 al 4\%. Los signos clínicos en seres humanos tras la infección natural (es decir, cuando el virus es transmitido por artrópodos) son similares a los de un resfriado que incluye fiebre, malestar, dolor corporal y cefalea durante la etapa inicial. La infección deriva en signología de afecciones en el sistema nervioso central en una alta proporción de las personas afectadas, que se manifiesta en somnolencia, convulsiones, coma y disfunción motriz. ${ }^{23}$ Las lesiones patológicas presentes en el cerebro de las personas con una presentación neurológica grave de la infección son acumulación perivascular de linfocitos y neutrófilos, necrosis multifocal y gliosis, ${ }^{24,25}$ tanto en la materia gris como en la blanca, siendo las regiones más afectadas el núcleo basal, tálamo y tallo cerebral; también se han observado lesiones en la médula espinal. ${ }^{26}$ En el $90 \%$ de los niños menores a 1 año se presenta el cuadro neurológico severo, ${ }^{27}$ con secuelas que pueden persistir por meses o años, o incluso ser permanentes. ${ }^{28}$ De las personas que sobreviven a la infección, el 30\% de los adultos y el 50\% de los niños desarrollan secuelas neurológicas entre las que se encuentran hemiplejía, cuadriplejía, pérdida de la capacidad intelectual, paranoia, cuadros de ansiedad y cambios en la conducta. ${ }^{29}$ En el caso de la infección por aerosoles, producto de accidentes de laboratorio, se ha documentado una mortalidad hasta del $40 \%{ }^{30}$ 


\section{Diagnóstico}

La estación del año, que determina la presencia de mosquitos, está asociada al diagnóstico clínico, que se basa en los signos ya mencionados. Estos comenzarán a presentarse pocos días después de la infección, una vez que el huésped desarrolla cierto grado de viremia y que el virus llega al SNC.31

En general los signos clínicos son de poca utilidad para el diagnóstico definitivo debido a que no son específicos y se comparten con otras enfermedades neurológicas en equinos, tales como encefalitis virales equinas del este, oeste o venezolana, mieloencefalopatía por herpes virus equino-1, meningoencefalitis bacterianas, rabia, mieloencefalitis protozoaria equina, leucoencefalomalacia por micotoxicosis, intoxicación por alcaloides de pirrolizidina, intoxicación con algas, o deficiencias nutricionales de tiamina o vitamina E. ${ }^{32}$ Sin embargo, establecer un diagnóstico definitivo es esencial para la implementación de medidas de control, por lo que es necesario recurrir a pruebas de laboratorio.

El diagnóstico serológico se realiza buscando anticuerpos lgM específicos contra el virus de la encefalitis equina del oeste. Se utilizan ensayos inmunoenzimáticos (ELISA), o bien de anticuerpos neutralizantes por la prueba de neutralización por reducción de placa (NRP), la cual no se recomienda en animales vacunados. También pueden ser de utilidad la prueba de inhibición de la hemaglutinación (HI) y la fijación del complemento (FC). La desventaja de estas últimas recae en las reacciones cruzadas, que se observan en un mayor porcentaje que en los ELISA de captura o la NRP. En el caso de la FC se ha de tomar en cuenta que los anticuerpos fijadores del complemento aparecen en etapas tardías de la infección y persisten por periodos cortos, lo que ocasiona falsos negativos. Por la presentación clínica de la enfermedad, se pensaría que es de utilidad la detección de anticuerpos (IgM) en el líquido cefalorraquídeo; sin embargo, esta técnica es eficiente sólo en casos de infecciones en humanos, ya que es menos sensible y específica en otras especies como los caballos, en comparación con la detección en suero. Es recomendable realizar más de una prueba en busca de anticuerpos lgM para aumentar el éxito del diagnóstico. ${ }^{32-35}$

Las pruebas serológicas con un aumento de cuatro veces en los títulos de anticuerpos se consideran como positivas. Este hallazgo es más contundente en caballos sin vacunar. Sin embargo, si el muestreo se realiza posterior al pico de producción de anticuerpos, es posible que no se obtenga un incremento de esta magnitud. ${ }^{32}$ Cuando esto sucede, el aislamiento viral puede ser una opción para determinar el agente causal. Para ello es recomendable utilizar tejido nervioso, en particular el cerebro, ya que los aislamientos virales a partir del suero son poco exitosos. Las líneas celulares en las que se puede intentar el aislamiento viral provienen de vertebrados (Vero, RF-13, Fibroblastos de embrión de pollo o pato y BHK) y de mosquitos. También pueden utilizarse modelos de infección en ratones o polluelos recién nacidos para recuperar el virus. ${ }^{33,35}$

La falta de éxito en el aislamiento viral hace que sea poco usado para el diagnóstico y que se utilice con mayor frecuencia para otros fines como la elaboración de vacunas. Para demostrar la presencia viral se prefieren técnicas como la inmunohistoquímica y la reacción en cadena de la polimerasa (PCR) de transcripción inversa (RT-PCR), con las que es posible identificar al virus en tejido nervioso (cerebro). Los resultados de estas pruebas pueden complementar al diagnóstico serológico. 33 
Las lesiones macroscópicas de la infección por EEO en el sistema nervioso central suelen ser inespecíficas, por lo que el diagnóstico es más preciso con el análisis histopatológico del tejido cerebral. La lesión típica es la inflamación severa de la materia gris, con degeneración neuronal, gliosis, manguitos perivasculares y hemorragias. La localización de las lesiones dentro del tejido nervioso puede ayudar a diferenciar la EEO de otras encefalopatías virales. ${ }^{33}$

Es importante enfatizar que, cuando se realiza la necropsia a un caballo, se debe tener en cuenta la protección del personal que la desarrolla, con el fin de prevenir su exposición a los fluidos corporales que se suelen esparcir en este procedimiento. ${ }^{36}$

\section{Tratamiento}

No existe tratamiento específico para la EEO, por lo cual su manejo se enfoca a la terapia de soporte. ${ }^{31}$ Se indica mantener una buena hidratación y equilibrio ácido-base, una nutrición adecuada, usar antiinflamatorios no esteroideos (AINE), dimetil sulfóxido (DMSO) y anticonvulsivos, así como proveer de una cama adecuada a los caballos, para prevenir úlceras por postración. ${ }^{1,31}$ Los animales que se recuperan pueden presentar signos nerviosos residuales de leves a graves, cuya seriedad depende de la variante viral que haya estado implicada en la infección. La mayoría de los equinos infectados por EEO se recuperan; sin embargo, la tasa de mortalidad va del 20 al 40\%.2,8,37 Los individuos con signos clínicos graves se asocian a una fase muy avanzada de la infección, por lo que generalmente mueren o se recomienda inducirles la eutanasia. ${ }^{36}$

\section{Medicina preventiva y control}

En México, la EEO es una afección de notificación inmediata obligatoria, ya que forma parte de las enfermedades del grupo 1: "plagas exóticas que no se encuentran en el territorio nacional, o que han sido erradicadas del país, y que por su rápida diseminación pueden afectar a la población animal terrestre y acuícola, y en algunos casos ser un riesgo para la salud pública" (Diario Oficial de la Federación, 2016). Los veterinarios que sospechen de un caso de encefalomielitis viral deben seguir las pautas nacionales y/o locales para la notificación y las pruebas de diagnóstico correspondientes. ${ }^{*}$ El Gobierno Federal debe, asimismo, notificar a la OIE algún brote de encefalomielitis viral en el país. Los requisitos para ello, así como las pautas de importación/exportación, pueden consultarse en el Código Sanitario para los Animales Terrestres de la OIE (OIE, 2018)anorexia y depresión intensa. En los casos graves, la enfermedad de los caballos evoluciona hacia la hiperexcitabilidad, ceguera, ataxia, depresión mental grave, postración, convulsiones y muerte. La infección por el virus de la encefalomielitis equina del Este (EEE. ${ }^{38}$

* https://www.gob.mx/cms/uploads/attachment/file/464519/Infograf_a_Encefalitis_Equina_del_Oeste.pdf.Tel.01(800)7512100, gestioncpa.dgsa@senasica.gob.mx, sive.dgsa@ senasica.gob.mx. 
Debido a que la EEO no es una enfermedad oficialmente reconocida en México, no existen vacunas disponibles, y la única autorizada en nuestro país es la utilizada para prevenir la EEV (EQUIVAC TC83, de virus activo modificado y aplicada anualmente antes de la época de lluvias, principalmente en las regiones endémicas del país). Por ello, es importante utilizar medidas para disminuir el riesgo de infección. Se sugiere alojar a los caballos en caballerizas controladas, especialmente durante los horarios de elevada actividad de los mosquitos. Puede ser útil el uso de mallas, repelentes y ventiladores, así como métodos de control de los mosquitos en el ambiente (como la fumigación y evitar los depósitos de agua estancada). Deben respetarse las cuarentenas y los controles de movimiento de animales aplicados durante brotes de la enfermedad, ya que son medidas indispensables para asegurar el éxito en la contención y el control de la enfermedad. 8,39

En los países en los que se reconocen las tres encefalitis (EEE, EEO y EEV), y que cuentan con vacunas autorizadas para los caballos, se recomienda la aplicación de las tres vacunas, aun cuando se haya diagnosticado la presencia de una sola de estas enfermedades. ${ }^{31}$ Los protocolos de vacunación deben seguir los lineamientos propuestos por la Asociación Americana de Especialistas en Equinos de EUA. ${ }^{40}$ En particular, la vacuna que utilizan contra la EEO es de virus completo inactivado con formalina y ha demostrado ser altamente eficaz en la protección contra la enfermedad clínica.

\section{Referencias}

1. CFSPH. Encefalomielitis equina: del este, del oeste y venezolana. The Center for Food Security \& Public Health. 2008;10(1-11). Disponible en: http://www. cfsph.iastate.edu/Factsheets/es/equine_encephalitides-es.pdf

2. Long MT. West nile virus and equine encephalitis viruses: New perspectives. Veterinary Clinics of North America-Equine Practice. 2014;30(3):523-42. https:// doi.org/10.1016/j.cveq.2014.08.009

3. Go YY, Balasuriya UBR, Lee C. Zoonotic encephalitides caused by arboviruses: transmission and epidemiology of alphaviruses and flaviviruses. Clin Exp Vacc Res. 2014;3(1):58. https://doi.org/10.7774/cevr.2014.3.1.58

4. Kuhn RJ. Togaviridae: The viruses and their replication. Fields Virology. 2007;1.

5. Senasica. Detecta Senasica casos de virus de encefalitis equina del Oeste. Senasica; 2019. Disponible en: https://www.gob.mx/pronabive/prensa/detecta-senasica-casos-de-virus-de-encefalitis-equina-del-oeste-194626?idiom=es

6. Weaver SC, Kang W, Shirako Y, Rumenapf T, Strauss EG, Strauss JH. Recombinational history and molecular evolution of western equine encephalomyelitis complex alphaviruses. J Virol. 1997;71(1):613-23.

7. Reisen WK, Meyer RP, Presser SB, Hardy JL. Effect of temperature on the transmission of western equine encephalomyelitis and St. Louis encephalitis viruses by Culex tarsalis (Diptera: Culicidae). J Med Entomol. 1993;30(1):151-60. https://doi.org/10.1093/jmedent/30.1.151

8. Simon LV, Fischer MA. Western equine encephalitis. Treasure Island (FL): StatPearls Publishing; 2019. 
9. McGowan JE, Bryan JA, Gregg MB. Surveillance of arboviral encephalitis in the united states, 1955-1971. Am J Epidemiol. 1973;97(3):199-207. https://doi. org/10.1093/oxfordjournals.aje.a 121500

10. Aréchiga-Ceballos N, Aguilar-Setién A. Alphaviral equine encephalomyelitis (Eastern, Western and Venezuelan). Revue Scientifique et Technique (International Office of Epizootics). 2015;34(2):491-501.

11. Batalla $D$, Mercado $S$. Detección de la actividad viral de las encefalitis equinas del este (EEE), oeste (EEO) y Venezuela (EEV), en diferentes regiones del país. Tecnica Pecuaria. 1966;23-6.

12. Campillo-Sáinz C. Incidencia de infecciones por Arbovirus encefalitógenos en México. Salud Publica de Mexico. 1965;7(3):385-8.

13. Hahn CS, Lustig S, Strauss EG, Strausst JH. Western equine encephalitis virus is a recombinant virus (RNA recombination/Alphavirus/evolution of RNA viruses). Proc Natl Acad Sci U S A. 1988;85:5997-6001.

14. Reisen WK, Chiles RE, Martinez VM, Fang Y, Green EN. Experimental infection of california birds with western equine encephalomyelitis and St. Louis encephalitis viruses. J Med Entomol. 2003;40(6):968-82. https://doi. org/10.1603/0022-2585-40.6.968.

15. Guy JS, Barnes HJ, Ficken MD, Smith LG, Emory WH, Wages DP. Decreased egg production in turkeys experimentally infected with eastern equine encephalitis virus or highlands J virus. Avian Dis. 2006;38(3):563. https://doi. org/10.2307/1592080

16. Lindstr K, Lundstr J. Male greenfinches (Carduelis chloris) with brighter ornaments have higher virus infection clearance rate. Behav Ecol Sociobiol. 2000;44-51.

17. Malkinson M, Banet $C$, Weisman $Y$, Pokamunski S, King R, Drouet MT, et al. Introduction of West Nile virus in the Middle East by migrating white storks. Emerg Infect Dis. 2002;8(4):392-97. https://doi.org/10.3201/eid0804.010217

18. Aguilar MJ. Pathological changes in brain and other target organs of infant and weanling mice after infection with non-neuroadapted Western equine encephalitis virus. Infec Immun. 1970;2(5):533-42.

19. Nagata LP, Hu WG, Parker M, Chau D, Rayner GA, Schmaltz FL, et al. Infectivity variation and genetic diversity among strains of Western equine encephalitis virus. J Gen Virol. 2006;87(8):2353-61. https://doi.org/10.1099/vir.0.81815-0

20. Monath TP, Kemp GE, Bruce Cropp C, Chandler FW, Monath TP, Kemp GE, et al. Necrotizing myocarditis in mice infected with western equine encephalitis virus: Clinical, electrocardiographic, and histopathologic correlations. J Infect Dis. 1978;138(1):59-66. https://doi.org/10.1093/infdis/138.1.59

21. Swearengen J. Biodefense research methodology and animal models, $2^{\mathrm{a}}$ ed. Boca Raton (FL): CRC Press; 2012. https://doi.org/10.1201/b11523

22. Acha PN, Szyfres B. Zoonoses and communicable diseases common to man and animals: Volume III. Parasitoses. PAHO Scientific and Technical Publication No. 580, III, $3^{a}$ ed.; 2005. 378pp. https://doi.org/10.1590/ S1135-57272005000300012

23. Bonilla NJ, De la Monte SM, De Urdaneta AG., Hutchins, GM, Castro F. The systemic pathology of venezuelan equine encephalitis virus infection in humans. Am J Trop Med Hyg. 1985;34(1):194-202. https://doi.org/10.4269/ ajtmh. 1985.34.194 
24. Anderson BA. Focal neurologic signs in western equine encephalitis. Can Med Assoc J. 1984;130(8):1019-21.

25. Rozdilsky B, Robertson HE, Chorney J. Western encephalitis: report of eight fatal cases: Saskatchewan epidemic, 1965. Can Med Assoc J. 1968;98:79-86

26. HurstEW. The histology of equine encephalomyelitis. J Exp Med. 1934;59:529-42.

27. Calisher $\mathrm{CH}$. Medically important arboviruses of the United States and Canada. Clin Microbiol Rev. 1994;7(1):89-116. https://doi.org/10.1128/CMR.7.1.89

28. Report C. West Nile virus disease and other arboviral diseases - United States, 2011. MMWR Morb Mortal Wkly Rep. 2012;61(27):510-4.

29. Herzon H, Shelton JT, Bruyn HE. Sequelae of Western equine and other arthropod-borne encephalitides. Neurology. 1957;7(8):535-5. https://doi. org/10.1212/WNL.7.8.535

30. Hanson RP, Sulkin SE, Buescher EL, Hammon WM, McKinney RW, Work TM. Arbovirus infections of laboratory workers. Science. 1967;158(3806):1283-6.

31. Reed DS, Glass PJ, Bakken RR, Barth JF, Lind CM, Da Silva L., et al. Combined alphavirus replicon particle vaccine induces durable and cross-protective immune responses against equine encephalitis viruses. J Virol. 2014;88(20):12077-86. https://doi.org/10.1128/jvi.01406-14

32. Doneley B. Disorders of the nervous system. Avian Medicine and Surgery in Practice. 2013;203-211. https://doi.org/10.1201/b15176-20

33. CFPSH. Eastern, Western and Venezuelan equine encephalomyelitis. Ames, IA: The Center for Food Security \& Public Heath; 2017. p. 1-9.

34. Long PO. Camelid vaccinations. En: Cebra C, Tibary A, Johnson LW, Anderson DE, Van Saun RJ, editores. Llama and alpaca care. Filadelfia: Saunders; 2014. p. 9-10. https://doi.org/10.1016/B978-1-4377-2352-6.00003-1

35. Orosz SE, Johnson-Delaney CA. Knottenbelt and Pascoe's color atlas of diseases and disorders of the horse. Filadelfia: Saunders; 2014. https://doi.org/10.1016/ C2010-0-66008-1

36. OIE, CDC, USDA, ISU. Eastern equine Western equine encephalomyelitis and Venezuelan equine Encephalomyelitis equine encephalomyelitis; 2015.

37. Hubálek Z, Rudolf I, Nowotny N. Arboviruses pathogenic for domestic and wild animals. Adv Virus Res. 2014;89. https://doi.org/10.1016/ B978-0-12-800172-1.00005-7

38. OIE. Encefalomielitis equina (del Este o del Oeste); 2018. p. 725-32.

39. Institute for International Cooperation in Animal Biologics. Encefalomielitis equina: del este, del oeste y venezolana. CFSPH. 2008;10:1-11.

40. AAEP. AAEP Infectious disease guidelines: Arboviruses; 2017. p. 1-4.

41. Mesa FA, Cárdenas JA, Villamil LC. Las encefalitis equinas en la salud pública. Bogotá: Universidad Nacional de Colombia; 2005. 